\title{
OFERTA RECREATIVA ADAPTADA AOS OBJETIVOS DE CRIAÇÃO DA UNIDADE DE CONSERVAÇÃO - RESERVA NATURAL MILITAR LA CALERA, CÓRDOBA - ARGENTINA
}

Joaquin Paez ${ }^{1}$

Juliana García ${ }^{2}$

\section{RESUMO}

O Estado argentino, como outros países, transformou algumas áreas militares em reservas naturais militares, seja por seu valor estratégico para a conservação dos recursos culturais e naturais ou para cumprir os tratados internacionais de superfície de conservação. Esta nova modalidade de unidades de conservação é a menos estudada do país. Este artigo apresenta um diagnóstico geral da Reserva Natural Militar La Calera (Córdoba, Argentina), com o fim de encontrar alternativas para o desenvolvimento correto de uma oferta de lazer adaptado aos objetivos da criação da unidade de conservação. Considerado este diagnóstico, conclui-se que a melhor solução seria criar um plano de gestão participativa de acordo com as normas estabelecidas pelo órgão responsável pela administração da área. Apresenta-se também parte do plano de uso público proposto pelos autores - o zoneamento mais especificamente - como exemplo a ser replicado em todas as outras reservas militares do país cujos problemas são similares.

Palavras-chave: Reserva natural militar, Plano de uso público, La Calera, Sierras Chicas, planejamento, gestão.

\section{RESUMEN}

El estado Argentino, al igual que otros países, ha transformado algunas áreas militares en reservas naturales militares ya sea por su valor estratégico para la conservación de sus recursos culturales y naturales o para cumplir tratados internacionales de superficie de conservación. Esta nueva modalidad de unidades de conservación es la que menos ha sido estudiada en el país. El siguiente artículo presenta un diagnóstico general de la Reserva Natural Militar La Calera (Córdoba, Argentina), con el fin de buscar alternativas que permitan el correcto desarrollo de una oferta recreativa adaptada a los objetivos de creación de la unidad de conservación. Analizado dicho diagnostico se concluye que la mejor solución sería crear un plan de manejo participativo de acuerdo con los padrones ya establecidos por el órgano encargado de su administración. También se muestra una parte de la propuesta de plan de uso público realizada por los autores, más específicamente la zonificación, como ejemplo a replicar en todas las demás reservas militares del país, las cuales tienen los mismos problemas.

Palabras clave: reserva natural militar, plan de uso público, La Calera, Sierras Chicas, planificación, gestión.

\footnotetext{
${ }^{1}$ Técnico em Turismo. Pós-graduação em integração regional e desenvolvimento sustentável. E-mail: joaquin.paez@live.com

${ }^{2}$ Técnico em Turismo. Guia de Trekking. E-mail: julygarcia89@hotmail.com
} 


\section{INTRODUÇÃO}

Este trabalho foi feito por profissionais em gestão voltada para o turismo e o estudo da biodiversidade, membros ativos de associações cívicas e grupos de participação local que trabalham pelos direitos humanos e o meio ambiente. A razão pela qual se optou pela abordagem deste problema decorre no interesse que os autores têm na consolidação dos objetivos da criação das reservas naturais, contribuindo assim para a continuidade das reservas que compõem o mesmo corredor biológico.

Foi escolhida a "Reserva Natural Militar La Calera" (RNMLC). Esta representa um problema geral de falta de gestão de todas as unidades de conservação que se estendem para o norte na encosta oriental das Sierras Chicas, (Córdoba, Argentina) diferindo delas somente pelo fato de ser uma Reserva Militar.

A RNMLC, assim como todas as reservas da região, não estabeleceu estratégias para garantir a oferta de lazer adequada, respeitando os objetivos da criação.

\section{METODOLOGIA}

Para realizar este trabalho, foi adotada uma abordagem quantitativa e qualitativa, utilizando estratégias de triangulação de métodos, fontes, investigadores, informações e teorias. Foram também definidos duas classes de pesquisa iniciando sob uma pesquisa exploratória seguida de uma pesquisa descritiva.

Diferentes procedimentos de coleta de dados foram combinados, tais como: entrevistas, pesquisas, observação direta e levantamentos bibliográficos. Definido o objetivo geral de pesquisar o desenvolvimento de atividades recreativas alternativas que não interferem nos princípios da conservação da RNMLC, foi determinada a necessidade de realizar um diagnóstico completo da área tendo em conta os seguintes objetivos específicos:

- Destacar os atrativos naturais e culturais e seu potencial turístico.

- Estabelecer que tipos de atividades recreativas podem ser desenvolvidas sem prejudicar a conservação da área.

- Delimitar os usos específicos para cada zona, tendo em conta as características de cada um.

- Definir o perfil do visitante potencial.

Finalmente foram analisados os dados obtidos no diagnóstico, concluindo com o desenvolvimento de um plano de uso público como uma aproximação de solução desse conflito em particular, como uma proposta para replicar em outras reservas militares do país. Este artigo só se referirá ao zoneamento deste plano de uso público.

\section{DIAGNÓSTICO GERAL}


Globalmente, as mudanças na cobertura e uso da terra são os resultados mais visíveis das modificações do homem sobre os ecossistemas terrestres (WENG; WEI, 2003). O uso da terra em geral é influenciado por fatores econômicos, culturais, políticos, históricos e de posse, em múltiplas escalas. $\mathrm{Na}$ Argentina, as políticas neoliberais implementadas desde os anos 90 produziram mudanças na política social e produtiva da agricultura e o desmatamento tem sido um dos principais promotores de mudanças no uso da terra (BRITOS; BARCHUK, 2008). A diminuição da cobertura florestal nativa provoca consequências graves, como a perda de serviços ambientais, entre os quais pode ser mencionado: captação de água, proteção do solo, regulação de ciclos de nutrientes, balanço do carbono atmosférico, redução dos efeitos da mudança climática global e o aporte de produtos naturais de valor social, cultural e comercial (COTBN, 2009).

No caso da Província de Córdoba, a situação florestal é critica, existindo muito poucos remanescentes de floresta densa, com árvores de grande porte (CABIDO; ZAK, 1999; ZAK; CABIDO, 2002; ZAK, 2008). Há menos de cem anos atrás, a província de Córdoba possuía 75\% (12 milhões de ha) de seu território coberto por florestas nativas, comumente chamado de Monte. No ano de 2009, as florestas ocupavam apenas 3,6\% (594 mil ha) e a vegetação nativa remanescente totalizava aproximadamente $12 \%$ da área total (1.980.000 ha) constituída de arbustos, silvados, savanas, pastagens, áreas rochosas, e/ou sistemas semelhantes aos anteriores (COTBN, op. cit).

As principais causas que levaram à perda do ecossistema florestal nativo nesta província foram o desmatamento e os incêndios causados pelas pressões do negócio imobiliário e agronegócio, captura de animais silvestres, exploração mineira, urbanização descontrolada, entre outros (COTBN, op. cit.).

\section{CONTEXTO HISTÓRICO REGIONAL}

A área onde hoje está o RNMLC foi povoada até depois da conquista espanhola por indígenas Comechingones, que chamaram o lugar "Quisquisacate". A partir do século XVII, estes povos nativos foram capturados pelos espanhóis para o serviço pessoal e edificação da cidade de Córdoba. A partir deste momento estes povos foram reconhecidos na cidade de Córdoba como "El pueblo de La Toma".

No século XVIII, havia menos de 400 nativos da região. Nesta época, o primeiro edifício "Estancia de Molina" e a primeira capela "Nuestra Señora de los Dolores" foram construídos. No início do século XX, inicia-se a exploração de granito e pedra calcária, fazendo com que o nome atual da cidade adjacente se tornasse "La Calera". Em 1942, as terras são atribuídas ao exército argentino. Em 1971 o governo inicia a construção da Estrada Nacional 20, o principal acesso ao RNMLC da cidade de Córdoba. Em 1974, a área é proposta como reserva de hídrica no Departamento de Áreas Naturais Protegidas. A partir de 1975 e até 1979, a área é chamada de "La Perla" e funcionaria então como centro secreto de detenção, tortura e extermínio pelo governo militar, lapso este pelo qual passaram mais de 3.000 reféns. Em 1978, o pedido de conservação da área é reiterado ante o Programa de Meio Ambiente das Nações Unidas 
(PNUMA). Em 1980 começam a chegar conscritos para cumprir o serviço militar obrigatório em "La Perla". Em 2000, entra em vigor uma medida cautelar de não modificação do território, pois a conservação do sítio é necessária para testemunhos oculares em investigações de desaparecimentos durante a ditadura militar. Trata-se de uma numerosa quantidade de túmulos $\mathrm{NN}^{3}$, uma das maiores da América do Sul. Em 2009, "La Perla" é então aberta ao público, como um espaço para o exercício da Memória e Promoção dos Direitos Humanos. Também em 2009 é declarada Reserva Natural Militar La Calera. Em 2011, é apresentado um projeto para declaração da área em parque nacional da memória. Finalmente, em 2012, é formado o comitê de gestão da Reserva.

\section{RESERVA DE NATUREZA MILITAR LA CALERA}

Reservas Naturais Militares são áreas militares, que após superar conflitos de defesa para o qual foram criados, são transformados em reservas naturais por seu valor estratégico de seus recursos culturais e naturais ou para cumprir tratados internacionais de superfície de conservação.

A RNMLC está localizada ao oeste da cidade de Córdoba, com uma área de 11.377 ha ${ }^{4}$. Dois terços da sua superfície correspondem ao Bosque Serrano, e um terço ao Espinal. As terras são de domínio privado, jurisdição nacional, administração nacional no âmbito do Ministério da Defesa Nacional e gestão conjunta com a Administração de Parques Nacionais.

Correspondente à declaração do Bosque Permanente 5 na encosta oriental das Sierras Chicas, a RNMLC dá início a uma continuidade de 10 reservas naturais até o norte da região de Sierras Chicas. A reserva visa conservar as atrações cênicas e permitir a realização de diversas atividades recreativas relacionadas aos problemas ambientais, voltados principalmente para estudantes de centros urbanos próximos. Contudo, a área hoje em dia tem outros usos (ver Figura 01). Atualmente o acesso a Reserva, exceto á La Perla, não é permitido pois o exército e APN ainda não estabeleceram estratégias de uso público. Entretanto pessoas entram clandestinamente para praticar trekking, mountain bike no caminho "La Ochoa/El Diquecito" e escalada em "El Horno".

\section{Identificação dos atrativos:}

A área do RNMLC possui 10 atrativos turísticos, dos quais a maioria deles está localizada na área oeste da mesma, no Bosque Serrano, estando de uma forma ou de outra relacionada com a paisagem. Enquanto ao lado leste, área do Espinal, inclui apenas "La Perla".

\footnotetext{
${ }^{3}$ Pessoas com identidade desconhecida.

${ }^{4}$ De acordo com o estudo de títulos pelos engenheiros Feijo Osorio, Sauchelli y Asociados em 1990.

${ }^{5}$ Resolução 1408/1961 sancionada pelo Ex Honorable Directorio do Instituto Provincial de Asuntos Agrários.
} 


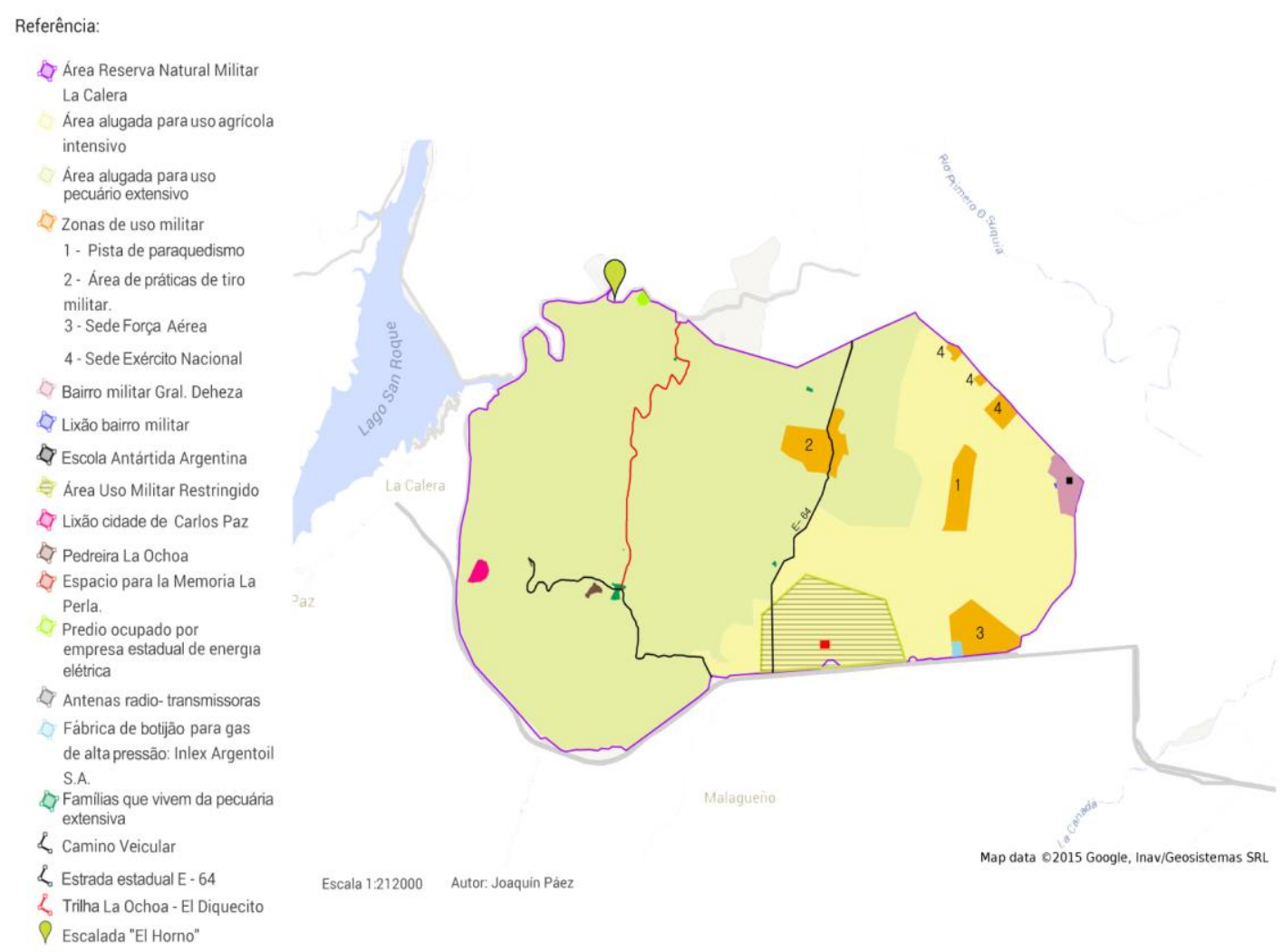

Figura 01- Uso atual da terra. Fonte: Joaquín Páez. Ano: 2015

Pode-se distinguir entre atrativos naturais e culturais. A área possui cinco atrativos culturais, com os quais pode-se desenvolver eixos de temas diferentes, porém unidos por uma característica comum: todos fazem parte do processo histórico de formação do território. A Capela de Nossa Senhora das Dores, imprime a história religiosa da região no século XVIII. La Estanzuela recorda a passagem de San Martin por as Sierras Chicas. Los Hornos são testemunhos do início da mineração na área. $\mathrm{O}$ Chalé Maria Teresa é um exemplo vivo das fazendas serranas de elite da época. Finalmente, o Espaço de Memória "La Perla" serve como espaço para o exercício da memória, a promoção e diálogo sobre as violações dos direitos humanos do passado e do presente.

"La Perla" já não se refere a um atrativo e sim um recurso concreto, pois no momento é o único elemento com aptidão e disponibilidade no qual a comunidade pode basear suas atividades turísticas.

Quanto aos atrativos naturais destaca-se a cachoeira La Campana, as vias de escalada "El Horno", Circuito Yocsina - El Diquecito e a caminhada "Agustín Tosco". A paisagem é um fator que os une, porém a essência da atratividade destes é baseada na prática de esportes. 


\section{Atividades turísticas adequadas a propor a cada área:}

Hoje, apesar da acessibilidade restrita aos funcionários administrativos, ao exército e inquilinos dos campos, ainda pratica-se trekking, escalada e mountain bike na região. Não existe necessidade para propor modificações às atividades existentes, mas sim adaptá-las à capacidade do solo mediante uma regulamentação adequada.

Outras atividades turísticas possíveis são: atividades de aviação, cavalgadas, caminhadas de até segundo grau ${ }^{6}$, cicloturismo, observação de flora e fauna, safári fotográfico e de sobrevivência. Entretanto, nenhuma das atividades acima mencionadas pode afetar a aparência do terreno e da vida selvagem.

\section{Possíveis áreas para o turismo:}

Após análise das leis, observações da área, os usos do solo identificados através de entrevistas, observação direta e literatura, foram identificadas três áreas possíveis para desenvolvimento de atividades turísticas (Figura 02)

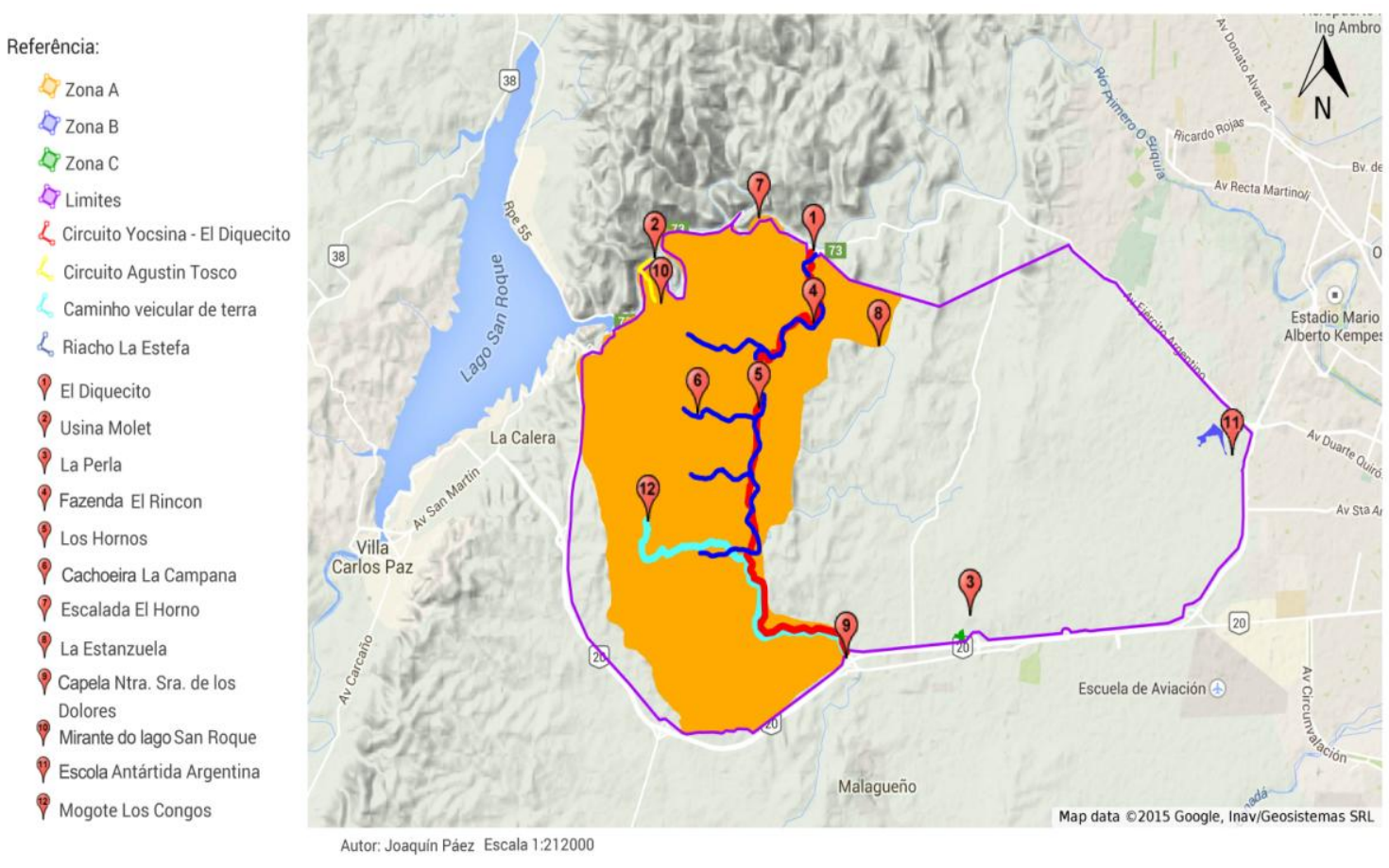

Figura 02 - Áreas potenciais para o desenvolvimento do turismo. Fonte: Joaquín Páez.

Ano: 2015

\section{Zona A:}

Esta zona é considerada uma prioridade para o desenvolvimento de turismo. Sua grande atração é devido às características da paisagem, pois possui trechos de bosque serrano maduro em melhor estado de conservação de toda a reserva, 
especialmente as relíquias de Orco Quebracho pertencentes à eco-região do Chaco Seco (Distrito Serrano). Nesta zona encontra-se o maior curso de água da reserva, o riacho La Estefa. A geografia física permite praticar esportes como o trekking e mountain bike.

Também neste setor estão os principais atrativos, tais como Los Hornos, cachoeira La Campana, Capela Nuestra Señora de los Dolores, La Estanzuela, e passeios de trekking "Agustin Tosco" e o circuito de mountain bike "Yocsina- El Diquecito".

A área é acessível pelo sul da estrada que vai em direção a La Ochoa, que parte da estrada nacional 20. O caminho começa como uma estrada de terra de 4,5 $\mathrm{km}$ adequado para a circulação de automóveis, depois torna-se uma trilha apta a pedestres ou ciclistas. Essa mesma estrada continua até o bairro El Diquecito na estrada estadual E-55, o que permite a entrada desde o norte. Também pelo lado norte, pode-se acessar pela trilha "Agustín Tosco", que começa a partir da Usina Molet. O fato de se ter acesso pelo setor norte e sul, permite a possível incorporação de recursos turísticos já consagrados, como: La Perla, Sanitarium El Diquecito e Usina Molet a um mesmo circuito turístico.

\section{Zona B:}

Esta zona é considerada de interesse para o uso público por suas possibilidades de realizar de atividades recreativas e educativas, principalmente aos moradores do bairro militar General Deheza, incluindo os estudantes da escola Antártida Argentina. Esta área tem um dos únicos trechos remanescentes de Espinal na reserva. Sendo a ecoregião Espinal (Distrito Algarrobo) a mais ameaçada no país devido ao desmatamento para a expansão da fronteira agrícola.

Esta área é acessada a partir do Distrito Militar General Deheza.

\section{Zona C:}

Localizada na entrada para "La Perla". Por sua acessibilidade e pelas condições de terreno, é adequada para a instalação de uma área de descanso e recreação disponível para todo publico, especialmente para os grandes contingentes estudantes que visitam "La Perla".

\section{Perfil do visitante potencial da RNMLC:}

Depois de inter-relacionar os dados recolhidos em questionários e entrevistas, conclui-se que a demanda potencial é feita por turistas excursionistas ${ }^{7}$ adultos entre $19 \mathrm{e}$ 45 anos de idade, de ambos os sexos e de um status sócio-econômico médio ou médioalto. Basicamente, são pessoas da capital de Córdoba e periferias, que desejam realizar atividades culturais e de lazer em contato com um ambiente natural. $O$ visitante é informado por comentários de amigos e familiares e também através de internet.

\section{PROPOSTA DE ZONEAMENTO}

\footnotetext{
${ }^{7}$ Visitantes de um dia.
} 
Pelo exposto, a RNMLC, por sua proximidade aos principais centros residenciais da província de Córdoba e pela singularidade de suas atrações naturais e culturais, possui potencial para desenvolver uma oferta turística variada, principalmente relacionada aos eixos históricos e esportivos. Para aumentar o potencial destes é necessário complementa-los entre si, já que a maioria é de baixa hierarquia. Ou seja: "Um atrativo capaz de motivar os fluxos turísticos locais e regionais que pode complementar outros atrativos de maior hierarquia" (DOMÍNGUES DE NAKAYAMA, 2006, p. 82).

Atualmente não foram estabelecidas estratégias para garantir a oferta recreativa adequada que respeite os objetivos de criação da reserva. Por esta razão, como proposta de solução projetou-se um plano de uso público. Neste são estabelecidas diretrizes de planejamento para regular as atividades de visitantes que frequentam a área com fins recreativos, interpretativos e/ou educacionais, de acordo com a metodologia proposta pela Administração de Parques Nacionais na Resolução 092/2003. Este plano visa ser um antecedente para a preparação de um plano definitivo, pois é considerado essencial alcançar a integração social através do planejamento participativo, incluindo os interesses de diferentes partes interessadas com instâncias de discussão e consenso. Também tem o objetivo estabelecer um precedente para incentivar o uso público planejando em todas as áreas militares do país, as quais não possuem nenhum progresso a este respeito.

Abaixo, como acabamento apresenta-se a proposta de zoneamento, o que representa somente uma etapa do plano de uso público realizado pelos autores.

\section{Zoneamento proposto:}

As zonas são representadas pelas cores na Figura 03. No caso de diferentes usos em uma mesma zona, eles serão representados por números.

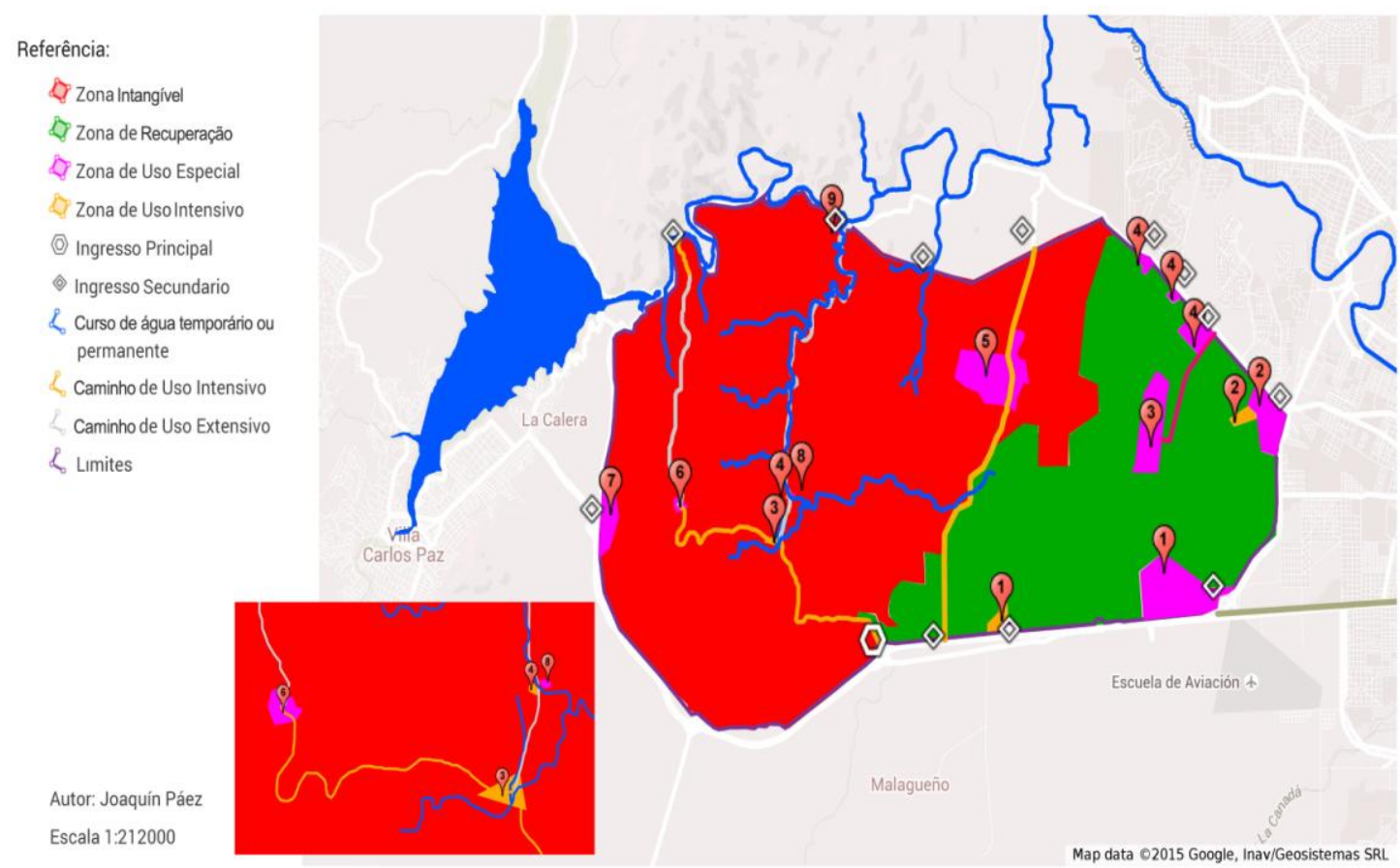


Figura 03 - Zoneamento proposto. Fonte: Joaquín Páez. Ano: 2015

\section{Zona Intangível:}

Área onde a natureza permanece intacta, não sendo capaz de fazer qualquer tipo de perturbação antrópica. Representa o mais alto grau de preservação. Nesta zona é feita a proteção integral dos ecossistemas naturais, recursos genéticos e culturais. $\mathrm{O}$ objetivo básico da gestão é conservar o ecossistema garantindo a evolução natural, razão pela qual os contratos de arrendamento agropecuários existentes poderão estar em vigor até que sejam cumpridos os prazos acordados e/ou até três anos transcorridos, ou o que ocorrer primeiro. Em respeito ao preenchimento dos contratos em vigor, não serão reconhecidos contratos de sublocação se existentes de fato.

Esta área é representada pelo Bosque Serrano, que supera a altura de 550 msnm. A zona é facilmente reconhecível, pois não tem sido utilizada para a agricultura. Superfície aproximada: 6.065 ha. Percentual aproximado do total: 50,8\%.

\section{Zona de uso público extensiva:}

Constituída principalmente por áreas naturais, podem apresentar alguma perturbação humana. O objetivo da gestão é manter um ambiente natural com o menor impacto humano possível, no entanto fornece acesso e instalações para fins educativos e recreativos a um baixo nível de intensidade. Este é representado por dois circuitos:

- Circuito Mogote Los Congos/Mirador Barragem San Roque. Extensão: 5 km

- Circuito La Ochoa - O Diquecito. Extensão: 9 km.

\section{Zona de uso público intensiva:}

Áreas com algum grau de alteração onde é desenvolvida a infraestrutura de atenção ao visitante. O objetivo de gestão é proporcionar recreação e educação ambiental. Esta zona poderá ter o maior impacto devido ao fato de que recebe e concentra um grande número de visitantes. Será uma zona cujas características de seu grau de uso natural permitam absorver os impactos dos visitantes. Serão desenvolvidas atividades interpretativas, recreativas e educativas, facilitando a apreciação e a compreensão da reserva por parte do visitante através do desenvolvimento de atividades de baixo impacto com controle contínuo da área. Entre caminhos e áreas, cobre uma porcentagem aproximada de $0,41 \%$ do total da reserva.

Os caminhos são:

- O caminho desde o ingresso até o Mogote Los Congos. Extensão: 8 km.

- Estrada Provincial E-64. Extensão: 9 km.

As zonas são:

1- Espaço para a Memória La Perla incluindo a área em torno da estrada de entrada. Superfície: 21,6 ha. Percentagem aproximada do total: $0,18 \%$. 
2- Oeste do Bairro Militar General Deheza. Remanescente de Bosque Espinal. Área: 13,5 ha. Percentagem aproximada do total: 0,12\%.

3- Aldeola La Ochoa. Área: 13,17 ha. Percentual aproximado do total: 0,11\%.

4- Esplanada adjacente ao Chalé Maria Teresa. Área: 0,46 ha. Percentagem aproximada do total: $0,004 \%$.

\section{Zona de Recuperação:}

Aquela que apresenta alterações e impactos de diferentes tipos de uso antrópico histórico prévio da criação da reserva. A área é considerada temporária porque uma vez restaurada, será redefinida como zona intangível. O objetivo geral é interromper a degradação dos recursos e restaurar o Bosque Espinal. Razão pela qual os contratos de arrendamento agropecuários existentes poderão estar em vigor até que sejam cumpridos os prazos acordados e/ou até três anos corridos, ou o que ocorrer primeiro. Em respeito aos contratos em vigor, não são reconhecidos contratos de sublocação se existentes de fato. Localizada no lado leste.

Superfície aproximada: 5.063 ha. Percentual aproximado do total: 42,8\%.

\section{Zona de Uso Especial:}

Área destinada geralmente aos usos relacionados com a administração necessária para o funcionamento da infraestrutura de área protegida. Neste caso se incluem usos militares, residenciais, e industriais. Percentagem total em relação à Reserva: $6 \%$.

1- Uso especial militar (Força Aérea) e industrial (InflexArgentoil S.A.). Superfície: 178,5 ha. Percentagem aproximada do total: 1,6\%.

2- Uso especial residencial (Bairro Militar General Deheza). Superfície: 80,81 ha. Percentual aproximado do total: $0,71 \%$.

3- Uso especial militar (Pista de aterrissagem e paraquedismo, e seu caminho de acesso). Superfície: 124,1 ha. Percentagem aproximada do total: 1,1\%. Extensão do caminho: $2,8 \mathrm{~km}$.

4- Uso especial militar (Prédios II Divisão do Exército do Norte). Superfície: 58,68 ha. Percentagem aproximada do total: 0,51\%.

5- Uso especial militar (Praticas de tiro). Não será utilizada até que sejam estabelecidas estratégias conjuntas entre o exército e APN, que confirmem a segurança dos turistas. Superfície: 190,9 ha. Percentagem aproximada do total: 1,7\%.

6- Uso especial antenas transmissoras. Os contratos de arrendamento existentes poderão estar em vigor até que sejam cumpridos os prazos acordados e/ou até três anos transcorridos, ou o que ocorrer primeiro. Posteriormente a área será redefinida como zona intangível. Superfície: 0,58 ha. Percentagem aproximada do total: $0,005 \%$. 
7- Uso especial Lixão Carlos Paz. Área considerada temporária porque uma vez restaurada, será redefinida como zona intangível. Superfície: 43,02 ha. Percentagem aproximada do total: $0,38 \%$.

8- Posto Norte. (Chalé Maria Teresa). Superfície: 0,016 ha. Percentagem aproximada do total: $0,0 \%$.

9- Sede de guardaparques. Superfície: 0,01 ha. Percentagem aproximada do total: $0,0 \%$

\section{REFERÊNCIAS BIBLIOGRÁFICAS}

ASTRADA, M. B.; ASTRADA M. O. La alta cuenca del río Suquía: recuperación del área para el desarrollo de la región. Córdoba. 2006

ÁVILA, M. Estructura del Sistema Turístico. Edição N¹. Córdoba. 2005.

BRITOS A.H.; BARCHUK A.H. Cambios en la cobertura y en el uso de la tierra en dos sitios del Chaco Arido del noroeste de Córdoba, Argentina. Agriscientia. 25(2): 97-110. 2008

CABIDO, M.R.; ZAK, M.R. Vegetación del Norte de Córdoba. Secretaría de Agricultura y Recursos Renovables de la Provincia de Córdoba. Agencia Córdoba Ambiente, 56 pp; 1999.

CINGOLANI, A. M. Propuesta de creación de un Parque Nacional en los campos del Tercer Cuerpo del Ejército. Córdoba. 2011

COMISIÓN PROVINCIAL POR LA MEMORIA. Disponible en < www.comisionporlamemoria.org >. Acceso 05/11/12

COTBN. Proyecto de ley de ordenamiento territorial de bosques nativos de la Provincia de Córdoba. 28 pp. 2009

DIEZ, E. Reseña Histórica de La Calera. Córdoba. 1945.

DOMÍNGUEZ DE NAKAYAMA, L. Relevamiento Turístico. Edição No 3, 6ta atualização. Centro de Estudios Turísticos. Instituto Superior de Turismo Sol, Santa Fe. 2006.

GRUPO ESCALERA. Disponible en < www.escalera.org.ar > Acceso 04/11/12

JAACKS, G. Informe $1^{\circ}$ Recorrida por el Campo del $3^{\circ}$ Cuerpo de Ejército en la Zona Metropolitana de la Ciudad de Córdoba. Córdoba. 23 de Maio de 2008.

JAACKS, G. Informe $2^{\circ}$ Recorrida por el Campo del $3^{\circ}$ Cuerpo de Ejército en la Zona Metropolitana de la Ciudad de Córdoba. Tramo abarcado: EI Diquecito-Los Hornos. Córdoba. 13 de Junho de 2008.

JAACKS, G. Informe N $^{\circ}$ 73/08PNQC: Informe sobre el Foro de Discusión Pública por el futuro de las tierras correspondientes al predio del $3^{\circ}$ Cuerpo de Ejército. Feito no auditorio Obispo Mercadillo de Córdoba, 7 de Abril de 2008. 
PADRE GRENÓN S. J. La Calera. Noticia ilustrada de la primera y aristocrática Villa veraniega de las Sierras de Córdoba. Córdoba. 1941.

PALACIOS ATILIO A., SPICOGNA J., BERNASCONI J., BUDINI I., RUFINI S., FERREYRA Y., SALGUERO E., DÍAZ ROMERO D. Decidirnos a Decidir. Edição $N^{\circ}$ 1. Córdoba. 2011.

WENG, Q.; WEI.Y.D. Land use and land cover change in China under the reform and globalization. AsianGeographer 22:1-. 2003.

ZAK, M.R. Patrones espaciales de la vegetación de la Provincia de Córdoba. Tesis Doctoral, Facultad de Ciencias Exactas, Físicas y Naturales, Universidad Nacional de Córdoba. 2008

ZAK, M.R.; CABIDO M. Spatial patterns of the Chaco vegetation of central Argentina: Integration of remote sensing and phytosociology. Applied Vegetation Science, 5, 213-226. 2002 